\title{
Biodiversity and Existing Condition of Coral Reef Ecosystem in Kondang Merak Beach Malang
}

\author{
Tarzan Purnomo \\ Biology Department, Faculty of \\ Mathematics and Natural Science \\ Universitas Negeri Surabaya \\ Surabaya, Indonesia \\ tarzanpurnomo@unesa.ac.id
}

\begin{abstract}
Coral reefs are one of the compilers of ecologically and economically important tropical marine ecosystems, but are very vulnerable to damage. Declining sea water quality due to climate change, coastal land use, and inaccurate coastal management patterns can threaten its sustainability. This study aims to determine the diversity and the condition of coral reefs in coastal Kondang Merak, Malang, East Java and external factor influence. The study used an observation method existing conditions in situ. Data was taken using the line transect method at 8 station, between stations 100 meters. Every one transect consist of 5 plots measuring 1x1 meter, 10-meter spacing plot. The research parameters measured included internal factors (type of coral reef, coral reef condition, total suspended solids, transparency, temperature, $\mathrm{pH}$, and water salinity), external factors (existing conditions of the beach and tourist behavior). The coral reefs found were documented and identified in the Ecology Laboratory, Department of Biology, Faculty of Mathematics and Natural Science, State University of Surabaya. Data diversity of coral reef are analyzed based on the calculation index diversity Shanon-Wiener and abundance relative Odum. Data water quality parameters and external conditions analyzed using descriptive qualitative. Based on the results of research known in the Kondang Merak beach, Malang found 28 species of coral reefs from 17 genera, diversity index of 1.99 including in the medium kategori. Oulophyllia bennettae is the most abundant coral reef species with a relative dominance of $34.61 \%$, followed by Porites lutea $31.03 \%$, Acropora robusta $6.18 \%$, and Plerogyra simplex $5.69 \%$. The majority of coral reefs are in damaged condition. Tourist stunt is an external factor causing dominant coral reef damage.
\end{abstract}

Keywords-biodiversity, conditions and threats, coral reefs, kondang merak beach, malang

\section{INTRODUCTION}

Coastal ecosystems are unique because they are a transitional area between terrestrial and marine ecosystems. The influence of these two ecosystems forms unique new characteristics, which are different from the two ecosystems that influence it [1]. Tropical coastal ecosystems usually consist of several supporting ecosystems in which mutually include coral reefs, mangroves and seagrass beds. Coral reef ecosystems occupy the front row, followed by seagrass and mangrove ecosystems. Coral reef ecosystems have specific characteristics and are very dependent on the condition of the surrounding waters. Coral reefs require waters with high brightness and adequate light intensity, therefore these ecosystems are usually in shallow exposure areas where sunlight penetrates to the bottom of the water [2].

Indonesia is the world's largest living coral exporter, because Indonesia is located in the heart of the global coral triangle. This location makes Indonesia has the largest number of coral species in the world, out of around 700 coral species in the world, 590 of them are in Indonesia. On the other hand, the coral triangle has an important function for human life, more than 120 million people depend on coral reefs and fisheries in the region. Coral triangle which includes Indonesia, Philippines, Malaysia, Timor-Leste, Papua New Guinea and the Solomon Islands, is an area that has the highest diversity of marine biodiversity in the world, especially coral reefs. In terms of coral reefs, coral is coral, which is a group of animals from the order Scleractinia that produce lime as the main forming of the reef. Reefs are limestone sedimentary rocks in the sea, which include live and dead corals attached to the limestone [3]. Lime sedimentation on reefs can come from corals or algae. Physically coral reefs are reefs that are formed from limestone produced by corals [3]. In Indonesia all reefs come from limestone, which is mostly produced by coral. Coral skeletons undergo erosion and accumulation of lation sticks to the bottom of the reef. At present the destruction of coral reefs, especially in Indonesia continues to increase rapidly. Coral reefs that are still in good condition only live around $6.2 \%$. This damage is caused by widespread pressure on coral reef ecosystems, partly because of fishing activities that are not environmentally friendly, land conversion in coastal areas, pollution, and tourism [4]. Although the trade quantity of coral reefs has been restricted by the Convention on International Trade in Endangered Species of Wild Fauna and Flora (CITES), but in fact the rate of exploitation of coral reefs is still high due to poor handling system.

The beaches on the southern coast of Malang district have a basic substrate composed of coral reefs, making them a tourist destination visited by many tourists. One of the impacts of this tourism activity is that the damage to coral reefs has been very alarming as happened at the coast of Goa Cina and Bale Kambang beaches. 
Condition Kondang Merak beach profile slightly sloping, at low tide the farthest expanse of the ocean floor in the form of reef corals are exposed to air and exposure to sunlight reaches as far as 200 meters from coastline. The edges are sandy and many are overgrown with coastal vegetation such as nyamplung etc. Existing conditions in the area surrounding the form of primary forests are still intact forest areas teak Perhutani, the fishing village, and area supporting tours and mangrove estuary. From the forest area flows the Kondang river which empties into the east end of the Kondang beach. The base of the waters is in the form of stretches of coral reefs and dead and slightly sandy corals. Different species of seaweed were also encountered. Because there is a fishing camp, fishing boat traffic every morning and evening crosses the coral reef ecosystem. Beautiful panorama makes this beach visited by many tourists.

Existence ecosystems of coral reefs in Kondang Merak beach is directly influenced by the waters quality and dynamics of existing conditions in the surrounding region [5]. With the opening of the southern cross path of East Java, there is a change in landscape due to the conversion of forests into roads, agricultural land, and tourist areas continues to increase. This has the potential to increase the rate of erosion and sedimentation so as to cause a decrease in the quality of coastal waters [6]. These dynamics can have a negative impact on coral reef ecosystems [7] in the southern coast of Malang. Changes in the structure of coral reef communities can include diversity, abundance, health, and coverage. Diversity and abundance of coral reefs affected by abiotic and biotic factors such as the transparency of the water, suspended solids or turbidity, temperature, salinity, and the condition of the existing environment, and killing by predators [8]. A very important component in composing coral reef ecosystems is rock corals. Other organisms such as fish, mollusks, echinoderms and seaweed utilize the environment of coral reefs as habitat, grow up, spawn, and find food. Remembering importance of coral reef ecosystems in food chain in the ocean, then its existence need to be preserved. For this reason, it is necessary to conduct research on the diversity and abundance of coral reefs on the Kondang Merak beach in Malang.

Coral reef ecosystems very influential affect life in the waters, because it plays an important role as a source of food, habitat, areas of care, as well as spawning ground for various marine organisms [9]. Changes in water quality caused by fishing practices that are not environmentally friendly, increased sediment input due to conversion of forests to agricultural land, as well as tourism activities can cause changes in the structure, composition, and quantitative value of coral reefs. This condition can cause a negative impact in the form of damage or mass death coral reefs. Based on this background, the purpose of this study is to find out the diversity and abundance of coral reefs on the Kondang Merak beach in Malang, East Java and the factors that influence them.

\section{METHODS}

This study uses an observational method of observing coral species in situ as well as observing the existing condition of the Kondang Merak beach. Data was taken using the line transect method at 8 stations (I-VIII), with a distance between stations of 100 meters. At each station a transect line is drawn from the coastline towards the sea. Each data transect was taken on 5 plots 1 x 1 meter, the distance between the plots was 10 meters. The types of corals found were documented and their species identified. The research parameters measured included internal factors (type of coral reef, coral reef condition, temperature, total suspended solids, transparency, $\mathrm{pH}$, and water salinity), external factors (existing conditions of the beach and tourist behavior). Identification types of coral reef conducted at the Laboratory of Ecology, Department of Biology, Faculty of Mathematics and Natural Science, State University of Surabaya. Data on coral reef diversity was analyzed quantitatively based on Shanon-Wiener diversity index calculations and Odum's relative abundance.

The diversity index $\left(\mathrm{H}^{\prime}\right)$ of coral reefs is calculated using the Shanon-Wiener index [10]:

$$
H^{\prime}=-\left(\sum p i \ln \ln p i\right)
$$

Information:

$\mathrm{H} '=$ species diversity index

$\mathrm{pi}=\mathrm{ni} / \mathrm{N}$

$\mathrm{ni}=$ number of individuals of each species

$\mathrm{N}=$ number of all individuals

with the following criteria:

$$
\begin{aligned}
& H^{\prime}>3.0 \text { : high diversity } \\
& 1<H^{\prime}<3 \text { : medium diversity } \\
& H^{\prime}<1 \text { : low diversity }
\end{aligned}
$$

The relative abundance of coral reef species is analyzed using the following formula [10]:

$$
K R_{i}=\frac{n_{i}}{N} \times 100 \%
$$

Information:

$\mathrm{KRi}=$ relative abundance

$\mathrm{ni}=$ number of individual types $\mathrm{i}$

$\mathrm{N}=$ total individual of all species

Data of physical-chemical parameters of waters include transparency, total suspended solids, temperature, DO, BOD, $\mathrm{CO}_{2}$, salinity, and $\mathrm{pH}$ of water, analyzed descriptively and compared with quality standards [11]. Existing condition data and tourist behavior on the Kondang Merak beach were analyzed descriptively qualitatively.

\section{RESULTS AND DISCUSSION}

Kondang Merak beach has a relatively flat profile, in the form of a bay, both sides of the mouth of the bay are protected by coral islands so they are relatively protected from the onslaught of the waves from the Indonesian ocean. At low tide the farthest expanse of coral reefs exposed to free air and exposed to sunlight distant reaches up to 200 meters from the shoreline. When the tide of water in the intertidal zone ranges from 0.5-5.6 meters and the penetration of sunlight penetrates to the bottom of the waters. When observing the farthest receding occurs around 180-200 meters from the coastline. The duration of the receding period reaches 1.5 2 hours. The results of the identification of coral reefs in the Kondang Merak beach, Malang found 28 types of coral reefs that are consist of 17 genera (Fig 1). 


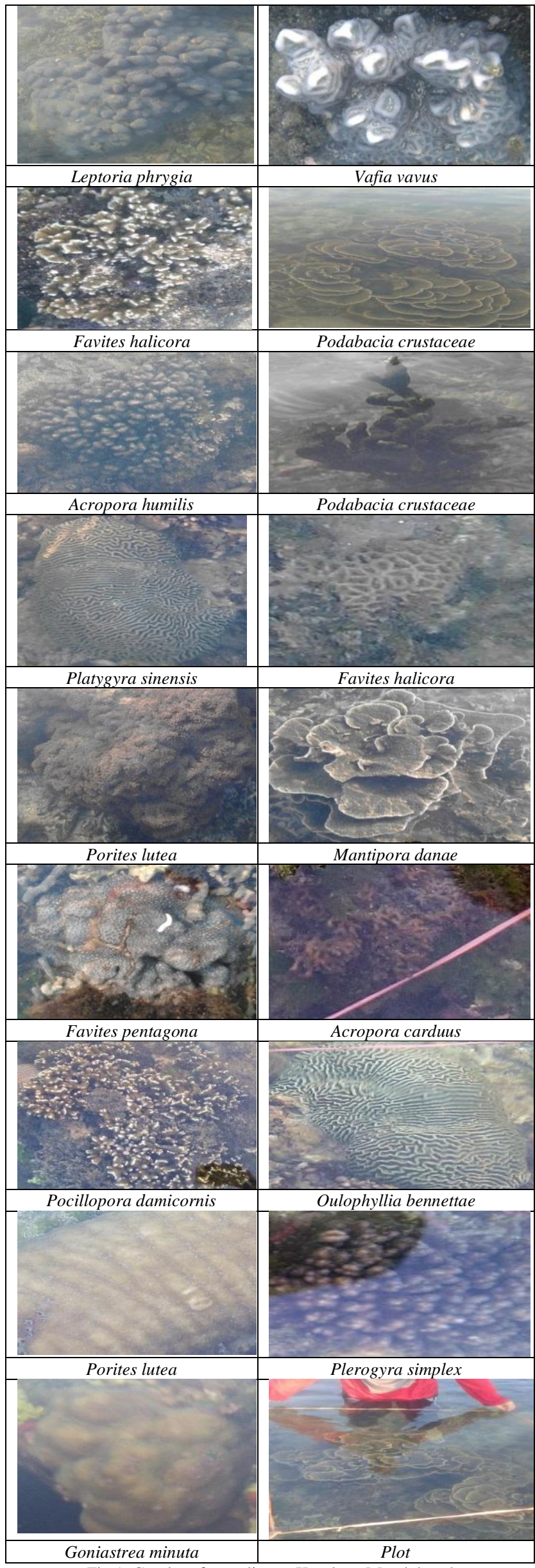

Fig 1. Coral reef sampling at Kondang Merak beach.
The diversity and number of species of coral reefs on the Kondang Merak beach are influenced by the water zone and sampling location. More coral reefs are found in the lower intertidal zone farthest from the coast, followed by the middle intertidal zone, and at least in the upper intertidal zone. This is due to the biggest external influence of tourists in the upper intertidal zone. In terms of location, coral reefs are most commonly found at station VIII, followed by stations V, VI, IV, VII, II, III and at least at station I (Figure 2). This is possible because the station VIII and V, the water is relatively deep, so when the maximum ebb still submerged in water approximately $0.3-1.2 \mathrm{~m}$ so it is relatively protected from exposure to direct sunlight and out of reach of tourists.

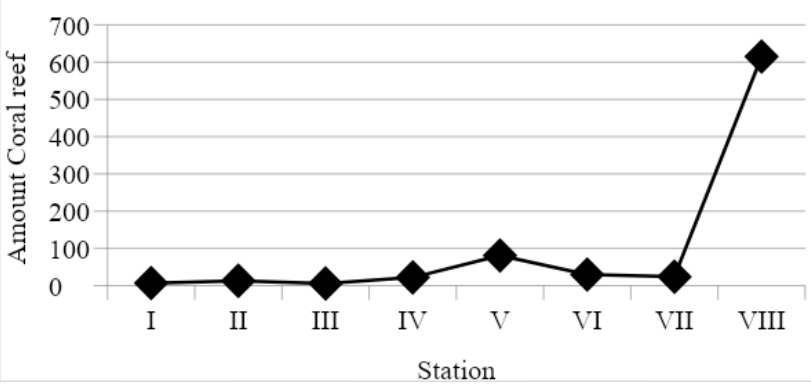

Fig. 2. Diagram of the number of coral reefs at each station on Kondang Merak beach, Malang, East Java

The diversity index of total coral reef in the intertidal zone of Kondang Merak beach in Malang is 1.99. This shows that the coral reef community on the Kondang Merak beach has diversity in the medium category [10]. The most abundant coral reefs are Oulophyllia bennettae with a relative abundance of $34.61 \%$, followed by Porites lutea $31.03 \%$, Acropora robusta $6.18 \%$, and Plerogyra simplex $5.69 \%$ (Table 1).

TABLE I. SPECIES, DiVERSITY INDEX, AND RELATIVE ABUNDANCE OF CORAL REEF IN KONDANG MERAK BEACH, MALANG, EAST JAVA

\begin{tabular}{|l|l|c|c|c|}
\hline No & \multicolumn{1}{|c|}{ Species Name } & NS & DI & RA (\%) \\
\hline 1 & Acropora abrotonoides & 5 & 0.0314 & 0.618 \\
\hline 2 & Acropora carduus & 22 & 0.0980 & 2,719 \\
\hline 3 & Acropora humilis & 25 & 0.1074 & 3,090 \\
\hline 4 & Acropora robusta & 50 & 0.1720 & 6,181 \\
\hline 5 & Rudis acropora & 25 & 0.1074 & 3,090 \\
\hline 6 & Favia vavus & 3 & 0.0208 & 0.371 \\
\hline 7 & Favites complonata & 1 & 0.0083 & 0.124 \\
\hline 8 & Favites halicora & 20 & 0.0915 & 2,472 \\
\hline 9 & Pentagona favites & 1 & 0.0083 & 0.124 \\
\hline 10 & Favites sp. & 1 & 0.0083 & 0.124 \\
\hline 11 & Fungia sp. & 1 & 0.0083 & 0.124 \\
\hline 12 & Galaxea astreata & 1 & 0.0083 & 0.124 \\
\hline 13 & Goniastrea minuta & 12 & 0.0625 & 1,483 \\
\hline 14 & Leptoria phrygia & 2 & 0.0148 & 0.247 \\
\hline 15 & Leptoseris scabra & 7 & 0.0411 & 0865 \\
\hline 16 & Jabe leptoseris & 0.0083 & 0.124 \\
\hline
\end{tabular}




\begin{tabular}{|l|l|c|c|c|}
\hline No & \multicolumn{1}{|c|}{ Species Name } & NS & DI & RA (\%) \\
\hline 17 & Montipora danae & 3 & 0.0208 & 0.371 \\
\hline 18 & Montipora sp. & 24 & 0.1044 & 2,966 \\
\hline 19 & Oulophyllia bennettae & 280 & 0.3672 & 34,610 \\
\hline 20 & Pachyseris speciose & 7 & 0.0411 & 0865 \\
\hline 21 & Platygyra sinensis & 2 & 0.0148 & 0.247 \\
\hline 22 & Plerogyra simplex & 46 & 0.1630 & 5,686 \\
\hline 23 & Pocillopor adamicornis & 5 & 0.0314 & 0.618 \\
\hline 24 & Podabacia crustaceae & 10 & 0.0543 & 1,236 \\
\hline 25 & Porites lutea & 251 & 0.3631 & 31,026 \\
\hline 26 & Porites sp. & 2 & 0.0148 & 0.247 \\
\hline 27 & Pseudosiderastrea sp. & 1 & 0.0083 & 0.124 \\
\hline 28 & Siderastrea siderea & 1 & 0.0083 & 0.124 \\
\hline & Total number & 809 & 1,9882 & 100.00 \\
\hline
\end{tabular}

The oceanographic factors of the physical and chemical parameters of the Kondang Merak coastal waters are still suitable for supporting the life of coral reefs. Water temperature ranges from $27.0-29.2^{\circ} \mathrm{C}$, infinite transparency, total suspended solids $0.311-0.414 \mathrm{~g}, \mathrm{pH} 7.9-8.1$, and salinity $35 \%$, DO 4.01-6.00 ppm, BOD 0.622-0.994 ppm, and $\mathrm{CO}_{2}$ $20.25-28.12 \mathrm{ppm}$. The results of these measurements indicate the quality of waters on the coast of Kondang Merak Malang are still in accordance with the quality standards of sea water quality [11], so it is very supportive for the life of coral reefs (Table 2).

TABLE II. OCEANOGRAPHIC PHYSICAL-CHEMICAL PARAMETERS IN KONDANG MERAK BEACH, MALANG EAST JAVA

\begin{tabular}{|c|c|c|c|}
\hline \multirow[t]{2}{*}{ Parameter } & \multicolumn{3}{|c|}{ Measurement Time } \\
\hline & Morning & Noon & Night \\
\hline \multicolumn{4}{|l|}{ Physics } \\
\hline Temperature $\left({ }^{\circ} \mathrm{C}\right)$ & 28.1 & 29.2 & 27.0 \\
\hline Transparency (m) & $\infty$ & $\infty$ & - \\
\hline Current Strength $(\mathrm{m} / \mathrm{s})$ & 0.067 & 0.275 & .284 \\
\hline TSS (g) & 0.414 & 0.311 & 0.320 \\
\hline Depth (m) & $\pm 0-1.2$ & $\pm 0.5-4.6$ & $\pm 0.5-5.6$ \\
\hline \multicolumn{4}{|l|}{ Chemistry } \\
\hline $\mathrm{DO}(\mathrm{mg} / \mathrm{l})$ & 4,665 & 6.002 & 4,010 \\
\hline $\mathrm{BOD}(\mathrm{mg} / \mathrm{l})$ & 0.718 & .994 & 0.622 \\
\hline $\mathrm{CO} 2(\mathrm{mg} / \mathrm{l})$ & 26,442 & 20.250 & 28,123 \\
\hline $\mathrm{pH}$ & 8.0 & 7.9 & 8.1 \\
\hline Salinity (\%) & 35 & 35 & 35 \\
\hline Hit the tourists & +++ & ++ & - \\
\hline
\end{tabular}

On the coast of Kondang Merak, Malang found 28 species of coral reefs consisting of 17 genera. In each station and intertidal zone, there are differences in the number of coral species found. The difference is due to the 8 stations have differences in the main influence of tourists who go down to the sea, step on, and take the reef. Likewise, among the three intertidal zones, the abundance is different, the highest abundance is in the lower intertidal zone and the lowest is in the upper intertidal zone. This is possible because in the lower intertidal zone, the depth of the water is relatively high, the strongest waves have the biggest currents and the water tanks are highest, so that at the farthest tide the majority are still submerged in water. While in the intertidal zone on a long exposure of air and sunlight can reach 1.52 hours each tidal period. This is because coral reefs are very sensitive to changes in the environment, especially temperature, salinity, sedimentation, eutrophication and require the quality of natural waters (pristine)[12]. Environmental temperature changes caused by global warming in the tropical waters that hit the year since 1998 has led to the bleaching of coral (coral bleaching) followed by mass mortality reaches $90-95 \%$. [13] noted that during the bleaching event, the average surface temperature of water in Indonesian waters was $2-3^{\circ} \mathrm{C}$ above normal temperatures. In addition to changes in temperature, changes in salinity will also affect coral reefs. This is in accordance with [14] explanation that high rainfall and surface material runoff from the mainland (mainland run off) can kill coral reefs through increased sediment and a decrease in salinity of sea water. The next effect is that excess nutrients (nutrient overload) contribute to the degradation of coral reefs because it triggers an increase in the growth of abundant macroalgae (overgrowth) on the reef.

The coral reef diversity index in Kondang Merak beach is 1.99 , including the medium category [10]. Means that on the coast of Kondang Merak has a diversity of coral reefs that are classified as moderate. This shows that the number of individuals of each coral type in a community is in relatively good condition [15]. The relatively high diversity index of coral reef shows that the distribution of individuals in each species is high and the stability of the community is also high. [10] states that a community is said to have high diversity if the community consists of many types with large abundance, equal or nearly equal. Of the 28 type of coral reefs which have highest diversity index is Oulophyllia bennettae amounting to $0.3672, \quad$ Porites lutea 0.3631 , Acropora $\quad$ robusta 0.1720 , and Plerogyra simplex 0.1630 . Coral reefs are a collection of compact and sturdy structures composed of skeletal bodies of benthic organisms that live in warm ocean waters with sufficient depth of light [16].

In the intertidal zone on the coast of Kondang Merak has a substrate type of sand and dead coral type and has relatively small currents and waves. This condition is actually very supportive of coral reef life [2]. However, due to the high pressure of external factors, especially the activities of a visitor who go down to sea at low tide, trampling on, and even take coral and animals that cause low diversity and density of coral reefs in this zone. Therefore, coral species that was found at least when compared to both the intertidal zone the other. In the middle and lower intertidal zones coral reefs are found more and conditions are better. This is due to strong currents and waves in the area is greater than upper intertidal zone, so that coral reef community gets better nutrient supply, to avoid the influence of sedimentation and tourism pressure. In the lower intertidal zone area has a substrate base consisting of coral reefs, coral reef abundance is best. This is because this zone is a wave breaking area of the Indonesian ocean, coral reefs are always washed away from sedimentation deposits, so that the conditions are the healthiest, grow well and the productivity of waters is high, indicated by the abundance of marine organisms in this zone. 
The diversity of coral reefs on the Kondang Merak beach is classified as a medium category [10]. On this coast found 28 species of coral, the number as many as 809 individuals. Dominant species are Oulophyllia bennettae (34.61\%), followed by Porites lutea (31.03\%), Acropora robusta (6.18\%), and Plerogyra simplex (5.69\%). The all four include into group coral has sturdy posture that is not easily damaged or broken when stepped travelers. The fewest types were found Favites complonata, Favites pentagona, Favites sp., Fungia sp., Galaxea astreata, Leptoseris yabei, Pseudosiderastrea sp., and Siderastrea siderea, each of which was only found one individual. The fewest groups are generally found to have a plate-shaped, flat, and thin body, so they are easily damaged, broken, broken when trampled by tourists. The many types of coral reefs found on this beach are also caused by the physicalchemical factors of the beach which meet the living conditions [9], that is temperature $27-29.2^{\circ} \mathrm{C}, \mathrm{pH} 7.9-8.1$, and salinity $35^{\circ} \%$

Oulophyllia bennettae, Porites lutea, Acropora robusta, and Plerogyra simplex are abundant and most dominant types of coral reefs in the intertidal zone of Kondang Merak beach. This is because in addition to environmental conditions such as physical-chemical factors the waters are very supportive of their existence, the species coral reefs are classified as massive coral, so they are more resistant to negative influences of tourists, among others not easily damaged or broken as a result of being trampled on, and cannot be taken using only hands. Oulophyllia bennettae are found in all zones intertidal beach Kondang Merak, as has the ability to adapt to the environment beaches exposed to air and the shape is massive thus able to live in various water conditions, especially high transparency, as well as the adaptive pressure.

Domination of Acropora species, because it is included in families that have high species diversity and fast reproductive rates. Acroporidae is a family with a rich type and mostly as a constituent of coral reefs in Indonesia. Family Acroporidae is represented by 156 species, of which almost $35 \%$ are coral reef compilers in the archipelago. According to Veron (1986) in [17] of 368 species, only 73 species have been recognized from Eastern Australia. However, the results of a recent survey conducted by Wallace that the Indonesian Archipelago is the center of Acropora diversity, with more than 90 species available and in an endemic list that has not been named. Family Acroporidae have distribution most commonly found in the area low nutrient and high energy (waves and currents). The level of integration of high colony and local rapid dispersion through fragmentation (asexual reproduction) so that it grows faster than the species others [17].

The survival of coral reefs is influenced by 6 environmental factors as limiting factors [18], namely light, temperature, salinity, water clarity, currents and substrate. Whereas [19] divided it into five factors, namely temperature, depth, light, salinity, and sedimentation factors. The measurement results show the oceanographic condition of Kondang Merak beach in conditions that are conducive to coral reef life.
The water transparency in the intertidal zone of Kondang Merak beach is infinite (5.6 meters), because sunlight penetrates to the bottom of the waters. This showed that level of clarity of the water in optimum conditions (>3 meters). According to [18] water transparency affects the quantity and quality of sunlight entering the waters. The quantity and quality of sunlight affects the quantity of energy supply by zooxathellae to carry out the process of photosynthesis. The results showed the transparency of water in the waters of Kondang Merak is infinite, meaning that sunlight penetrates to the bottom of the water to a depth of 5.6 meters so that the photosynthetic rate of zooxathellae is optimal. Hight level of brightness of the water causes the sun able to penetrate to the bottom of the waters where coral reefs are located. The sunlight plays an important role in the formation of coral reefs due to sunlight determines continuity photosynthesis process algae symbionts in the coral tissue (zooxanthellae). Without enough light, the rate of photosynthesis will decrease and together with the ability of corals to produce calcium carbonate and form reef structures will also be reduced [19].

Total suspended solids in the waters of Kondang Merak amounted to 0.311-0.414 grams, which is a small amount so that the life of coral reefs is not disrupted. Suspended solids affect the brightness of the water because in addition to causing turbidity or water turbidity, it also absorbs incoming light thereby reducing sunlight penetration into the water. Consequently, it can reduce the brightness and rate of photosynthesis. The bad effects of suspended solids include clogging pores on coral reefs, causing their death.

The depth of the water also determines coral growth. The influence of depth is related to other environmental factors such as light, movement of water currents, temperature, and salinity. In this research, observation of the diversity of coral reefs on the beach Kondang Merak, carried out at a depth of 0- 4 meters, so there are many coral reefs can be found. [2] states that in general the depth that is still feasible for coral growth is between 10-15 meters. Growth coral for the increasing depth depending on the species and environmental factors. The deeper waters of the growth and diversity of its increasingly decreased. Coral reef communities are more diverse at a depth of 3 meters compared to a depth of 10 meters [2].

Temperature is a limiting factor for the growth and distribution of coral reefs because it affects the process of photosynthesis and its metabolism [18];[19]. Temperature in the waters of Kondang Merak range $27^{\circ} \mathrm{C}$ $29.2^{\circ} \mathrm{C}$, therefore coral reefs can grow well, so that to a diversity coral reef at Kondang Merak beach is still quite good. Coral reefs can live optimally in the temperature range of $28-32^{\circ} \mathrm{C}$ [18]. [20] states that coral reefs can grow at temperatures of $18^{\circ}-36^{\circ} \mathrm{C}$ and optimum growth occurs in waters with an average annual temperature of $26^{\circ}$ $29^{\circ} \mathrm{C}$. According to [12] changes in temperature on corals can cause a decline in response to a meal, reducing the average reproduction, lots of mucus and the process of photosynthesis and respiration decreases. Coral reefs are one of the creatures that live on the seabed. Coral reefs function as habitat for marine plants, marine animals, and microorganisms. As with plants, coral reefs also carry out 
photosynthesis and produce oxygen. Therefore, coral reefs need sunlight to live.

To be able to grow and reproduce properly, coral reefs need optimal environmental conditions, namely in warm waters with ambient temperatures above $20^{\circ} \mathrm{C}$, clear and nonpolluting, and light penetration to the bottom of the waters [2]. Coral reefs need sunlight for photosynthesis. Coral reef-forming polyps located at the top of coral reefs can capture food that is carried by ocean currents and carry out photosynthesis [2]. Therefore, oxygen from photosynthesis dissolved in water can be utilized by other marine organism.

Waters of Kondang Merak has a pH of 7.9-8.1 so that it optimally supports the life of coral reefs. Most aquatic organism is sensitive to changes in $\mathrm{pH}$ and prefer a $\mathrm{pH}$ between 7.0-8.5. Every aquatic organism has different tolerance to changes in $\mathrm{pH}$ [21]. In general, the optimum $\mathrm{pH}$ for coral reef growth is in the range of 8.2-8.5 [19].

Coral reefs are very sensitive to changes in salinity that are higher or lower than normal salinity that is $30-35 \%$. The optimum salinity for coral growth is $32 \% 0-35 \%$ [ [19]. Salinity in the Kondang Merak coastal waters 35\%, thus very suitable for coral growth.

\section{CONCLUSION}

It was observed that, the coral reefs at the edge of the beach, which distance of 1-4 meters from the coastline to experience the level of damage to the highest. That is due to human activities, especially tourists. According to [22] activities that damage coral reefs are the development of coastal areas, rock mining, over-exploitation, destructive fishing, and intensive recreational use.

External factors that cause damage to coral reef ecosystems are many tourists who come down to the sea and step on the coral reefs at low tide. Some people dive for to take a coral as a collection at home, as well as the entry of muddy water flow of the river Kondang in the rainy season. These local tourists take anything that is visible, corals, mollusks, gastropods, bivalves, echinoderms, crustaceans, worms, and seaweed just for toys. These various organisms are then left on the beach when they leave the beach [4]; [23]. In addition, sea water pollution in the form of plastic waste is increasingly worrying. Garbage that is thrown away and come running into the sea to cover the coral reefs that hinder the process of photosynthesis and disrupt ecosystems. Agriculture in the upstream and Kondang river watersheds also contributes to the destruction of coral reefs. Especially related to erosion, sedimentation, the use of chemical fertilizers and pesticides that enter the Kondang Merak beach through river water flow. In addition, the traffic of fishing boats and boats that throw anchors also triggers the destruction of coral reefs. Because, anchors can accidentally hit coral reefs. If so the results of the fish obtained are not compatible with the sustainability of coral reefs in the long.

\section{ACKNOWLEDGMENT}

The author would like to thank Indonesia government was given grant for this research.

\section{REFERENCES}

[1] D. G. Bengen, "Coastal and marine ecosystems and resources and integrated and sustainable management, "Paper presented at the Proceedings of the Integrated Coastal Area Management Training, Bogor, 29 October - 3 November, 2002.

[2] P. Castro and M. E. Huber, "Marine Biology," 5th Ed, New York: Mc Graw Hill International, pp. 119-125, 2005.

[3] J. L. Sumich and G. H. Dudley, Laboratory and field investigations in marine biology. Ed.5, 1992.

[4] T. Purnomo, "The effect of tourism on the sustainability of Kondang Merak beach South Malang's," Paper for National Biology Seminar, Surabaya State University, 2018.

[5] T. Purnomo, "Existing environmental conditions and their effects on the quality of the waters of Kondang Merak beach," Paper for National Biology Seminar 2019, Surabaya State University, 2019.

[6] Saptari, "Forms of soil and coral reef ecosystems," J. of Marine Sci., vol.2, pp.60-62, 2008.

[7] M. Simanjuntak, "Relationship between chemical, and physical environment parameters to the distribution of plankton in the East Belitung waters, Bangka Belitung," J. of Fish, vol. 9, pp. 31-45, 2009.

[8] R. A. Hutagalung, "Lombok frags-the first sustainable coral cultivation on Indonesia for trade and reef conservation," The 9th International Aquarium Fish \& Accessories Exhibition \& Conference, Aquarama, Singapore, 2005.

[9] J. W. Nybakken, "Readings in marine ecology," Ed.2., pp.289291. 1986

[10] E. P. Odum, Fundamentals of Ecology, WB Saunders Co. Philadelphia, 1993.

[11] MENLH. Decree of the Minister of Environment Number: 51/MENLH/ 2004. Concerning the Determination of Sea Water Quality Standards in a Set of Regulations in the Environmental Field. Jakarta, 2004.

[12] Dubinsky, Z. 1990. Ecosystem of the World 25. Coral Reffs. Elsivier Amsterdam. Oxford New York. Tokyo, $550 \mathrm{p}$.

[13] Mustofa, "Marine coral ecosystem," J. of Educ., vol.2, pp. 60-66, 2002.

[14] W. Hadie, "Conservation of coral reefs through the cultivation of ornamental coral as an export commodity," J. of Exacta Factor Sci., vol. 1, pp. 60-79, 2008 .

[15] C. J. Krebs, Ecology, The Experimental Analysis of Distribution and Abundance, New York: Haper and Row Publication, 1972.

[16] J. S. Levinton, Marine Ecology. New Jersey: Piece Hall Inc., Engle Wood Chiffs, 1988 .

[17] T. Tomascik, A. J. Mah, A. Nontji, and M. K. Moosa, The Ecology of Indonesian Seas, Part I., Singapore: Periplus Editions (HK) Ltd, 1997

[18] A. Nontji, Sea Nusantara. Third Matter. Jakarta: Delay Publisher. 2002.

[19] J. W. Nybakken, Marine Biology, An Ecological Approach (translation by Eidman, H. Muhamad et al., first edition). Jakarta: PT. Gramedia, 1992.

[20] C. Birkeland, Life and Death of Coral Reefs, Chapman and Hall. International Thomson publishing, 1997.

[21] A. T. Sastrawijaya, Environmental Pollution. Jakarta: PT. Rineka Cipta, 2000.

[22] M. K. Moosa and Suharsono, "Rehabilitation and management of coral reefs: an effort towards the sustainable use of coral reef resources," Proceedings of the National Seminar on Management of Coral Reefs, Indonesian Institute of Sciences. Jakarta, 1995.

[23] Haryati, "Local wisdom of picking the sea of Kondang Merak," UB Malang Marine J., vol.2, pp. 12-16, 2006.

[24] Dahuri. Waters in the Coastal Seas. Gamma Journal, vol. 3, pp.3-5, 2004. 